\title{
Short communication: Parameters of abomasal emptying and glucose-insulin dynamics in Holstein-Friesian calves at 2 ages and 2 levels of milk replacer intake
}

\author{
P. Stahel, ${ }^{*}$ J. A. R. MacPherson, $\dagger$ H. Berends, $\ddagger$ M. A. Steele, $†$ and J. P. Cant ${ }^{* 1}$ \\ *Department of Animal Biosciences, University of Guelph, Ontario N1G 2W1, Canada \\ †Department of Agricultural, Food, and Nutritional Science, University of Alberta, Edmonton, T6G 2P5, Canada \\ $\ddagger$ Trouw Nutrition R\&D, PO Box 220, 5830 AE, Boxmeer, the Netherlands
}

\begin{abstract}
Elevated planes of nutrition in the preweaning period of dairy calf management can increase average daily gain, shorten age at puberty, and increase milk yield. In a previous study, 12 Holstein calves were fed 2 meals/d of 4 or $2 \mathrm{~L}$ milk replacer up to $7 \mathrm{wk}$ of age. The objective of the current study was to estimate parameters of abomasal emptying and glucose-insulin dynamics in these calves by fitting a mechanistic model to postprandial appearances of plasma glucose, insulin, and the abomasal emptying marker acetaminophen measured at 4 and 7 wk of age. Higher intake of milk replacer resulted in longer bouts of abomasal emptying at a slower rate. Parameters of glucose and insulin dynamics were not affected by milk replacer intake. However, older calves had decreased insulin-stimulated glucose utilization indicating impaired insulin sensitivity, as well as increased pancreatic responsiveness. Neither of these effects were apparent from i.v. glucose tolerance tests on the calves and may have been related to postprandial gut hormone release. Effects of age on parameters of glucose-insulin dynamics were larger than effects of milk replacer intake. Conversely, effects of milk replacer intake on abomasal emptying were larger than effects of age.
\end{abstract}

Key words: milk replacer, abomasal emptying, insulin sensitivity, pancreatic responsiveness, mechanistic model

\section{Short Communication}

The anabolic hormone insulin, secreted from the endocrine pancreas, exerts effects on glucose metabolism pathways in tissues to a degree that reflects the

Received October 28, 2016.

Accepted February 28, 2017.

${ }^{1}$ Corresponding author: jcant@uoguelph.ca sensitivity of those tissues to the hormone. Plasma glucose and insulin concentrations following an i.v. bolus of glucose can be used to estimate parameters describing pancreatic responsiveness to glucose, insulin sensitivity at target tissues, and the ability of glucose to stimulate its own disposal, called glucose effectiveness (Pacini and Bergman, 1986). These 3 parameters are good indicators of the anabolic state of animals and their ability to respond to dietary nutrients (Wolever and Mehling, 2002; Short et al., 2003). An oral glucose dose is much easier to deliver and more nutritionally relevant than an i.v. bolus, but estimation of glucose-insulin parameters from postprandial curves is complicated by an unknown rate of appearance of glucose into the circulation. Recently, we developed a mathematical model of the mixed-meal tolerance test (Stahel et al., 2016), in which gastric emptying dynamics are fit from appearance of a marker such as acetaminophen (Ac) in plasma (Marshall et al., 2005), and gastric emptying informs glucose appearance rates to solve the oral appearance dilemma. The purpose of the current work was to fit the Stahel et al. (2016) model to postprandial plasma glucose, insulin, and Ac curves in female Holstein-Friesian calves at 4 and $7 \mathrm{wk}$ of age, fed either low $(4 \mathrm{~L} / \mathrm{d})$ or high $(8 \mathrm{~L} / \mathrm{d})$ volumes of milk replacer (MR), from MacPherson et al. (2016), to assess treatment effects on parameters of abomasal emptying and glucose-insulin dynamics during feeding. Analyses before development of the model were limited to estimates of peak concentrations, times to peak concentration, and areas under the curve (AUC). The modeling analysis permits biologically meaningful parameters of pancreatic responsiveness, insulin sensitivity, and glucose effectiveness to be estimated in the postprandial period, as opposed to the fasted state of an i.v. glucose tolerance test. Insulin sensitivity indices for the fasted state, calculated from glucose and insulin concentrations during the first $30 \mathrm{~min}$ of an i.v. test, were not different between calf ages or MR allowances (MacPherson et al., 2016). We hypothesized that 
glucose-insulin dynamics following a meal could differ from those in the fasted state because of the role of gut peptides, such as incretins, in the postprandial response (D'Alessio et al., 2007; Woerle et al., 2012).

Postprandial glucose, insulin, and Ac time-course data were obtained from MacPherson et al. (2016). Briefly, 12 Holstein-Friesian calves were blocked in pairs with a similar parity of dam and given $4 \mathrm{~L}$ of the same previously-frozen colostrum within $6 \mathrm{~h}$ of birth. Calves were fed either low $(4 \mathrm{~L} / \mathrm{d})$ or high $(8 \mathrm{~L} / \mathrm{d})$ volumes of MR (150 g/L of DM; $24 \%$ CP, $18 \%$ crude fat, and $45.2 \%$ lactose on a DM basis; Trouw Nutrition, Deventer, the Netherlands) given in 2 equal meals per day from 1 to $7 \mathrm{wk}$ of age (MacPherson et al., 2016). At 4 and $7 \mathrm{wk}$ of age, blood samples were taken from a jugular vein catheter at $-30,30,60,90,120,150,180,210,240$, 300,360 , and $420 \mathrm{~min}$ relative to a meal containing 150 $\mathrm{mg} / \mathrm{kg}$ of metabolic BW $\left(\mathrm{BW}^{0.75}\right)$ of $\mathrm{Ac}$ as an abomasal emptying marker. All animal procedures complied with the Dutch Law on Experimental Animals, and the ETS123 (Council of Europe, 1986) and were approved by the Animal Care and Use Committee at Utrecht University. Plasma was analyzed for concentrations of Ac $\left(\mathbf{c} \mathbf{A} \mathbf{c}_{\mathbf{P}}\right)$, glucose $\left(\mathbf{c G l}_{\mathbf{P}}\right)$, and insulin $\left(\mathbf{c I n}_{\mathbf{P}}\right)$.

The Stahel et al. (2016) model describes masses of glucose, insulin, and Ac in plasma as differential equations of input minus output. Input to the plasma Ac pool is based on fast, slow, or zero abomasal emptying according to first-order rate constants $\left(\mathbf{k}_{\mathrm{SP}, 3}, \mathbf{k}_{\mathrm{SP}, 2}\right)$ and 0 , respectively, assigned to successive 30 -min blood sampling intervals. Output is due to first-order elimination according to rate constant $\mathrm{k}_{\mathrm{Ac}, \mathrm{UAc}}$. Concentrations of Ac in plasma are calculated by dividing plasma Ac mass by $0.9 \mathrm{BW}$, accounting for volume of distribution (0.67 BW; Janus et al., 2003) and first-pass splanchnic metabolism of the oral dose (Cant et al., 2005). Abomasal emptying of carbohydrate proceeds according to the Ac rate constants but, because of additional time for intestinal carbohydrate hydrolysis and absorption, appearance of exogenous glucose in plasma lags behind Ac appearance by the time lag between stomach and plasma $\left(\mathbf{T}_{\text {lag,sp }}\right)$ in minutes. A fixed $50 \%$ of the consumed glucose + galactose is assumed to appear as glucose in plasma, with the remainder lost to first-pass splanchnic metabolism. Endogenous glucose production $\left(\mathbf{P G l}_{\text {end }}\right)$ is maintained at a constant, zero-order flux, and irreversible loss of glucose is a function of $\mathrm{cGl}_{\mathrm{P}}$ and the insulin signal (Is) according to a glucose effectiveness constant $\left(\mathbf{k}_{\mathrm{Gl}, \mathrm{UGl}}\right)$ and an insulin sensitivity constant $\left(\mathbf{k}_{\mathrm{Is}, \mathrm{UGl}}\right)$. Insulin is released from the pancreas according to a sigmoidal Hill equation of 3 parameters, where $\mathrm{V}_{\mathrm{PIn}}$ is the maximum rate of insulin release, $\mathrm{K}_{\mathrm{Gl} \text {,PIn }}$ is a Michaelis-Menten parameter describing dependence on $\mathrm{cGl}_{\mathrm{P}}$, and the exponent (exp) for the production $(\mathbf{P})$ of insulin (In) is the Hill coefficient that sets the maximum acceleration of insulin release (i.e., at the inflection point). This inflection-point slope represents pancreatic responsiveness. Elimination of insulin from plasma follows first-order kinetics according to rate constant $\mathrm{k}_{\text {In,UIn }}$. The Is lags behind $\mathrm{cIn}_{\mathrm{P}}$ by $\mathrm{T}_{\text {lag,IS }}$ minutes, representing a time delay for insulin signaling to occur.

Although the model accounts for variation in $\mathrm{cAc}_{\mathrm{P}}$, $\mathrm{cGl}_{\mathrm{P}}$, and $\mathrm{cIn}_{\mathrm{P}}$ due to several sources, it does not also consider variation due to differences between calves and weeks in volumes of distribution and first-pass extraction percentages. The model was written in ACSLX (Aegis Technologies Group Inc., Orlando, FL) and solved with a 4th-order Runge-Kutta algorithm using an integration step size of $0.002 \mathrm{~min}$. For each calf at each week, the parameters of Ac kinetics $\left(\mathrm{k}_{\mathrm{SP}, 2}\right.$, $\mathrm{k}_{\mathrm{SP}, 3}$, and $\left.\mathrm{k}_{\mathrm{Ac}, \mathrm{UAc}}\right)$ were estimated using Microsoft Excel Solver (Microsoft Corp., Redmond, WA), and the parameters of glucose-insulin dynamics $\left(\mathrm{PGl}_{\mathrm{end}}, \mathrm{k}_{\mathrm{Gl}, \mathrm{UGl}}\right.$, $\mathrm{k}_{\mathrm{Is}, \mathrm{UGl}}, \mathrm{T}_{\mathrm{lag}, \mathrm{SP}}, \mathrm{V}_{\mathrm{PIn}}, \mathrm{K}_{\mathrm{Gl}, \mathrm{PIn}}$, $\exp _{\mathrm{PIn}}$, initial Is, $\mathrm{T}_{\mathrm{lag}, \mathrm{IS}}$, and $\mathrm{k}_{\text {In,UIn }}$ ) were estimated with a differential evolution algorithm, as previously described (Stahel et al., 2016). Both procedures minimized residual sums of squares between predicted and observed $\mathrm{cGl}_{\mathrm{P}}, \mathrm{cIn}_{\mathrm{P}}$ and $\mathrm{cAc}_{\mathrm{P}}$. A root mean square prediction error was calculated to represent goodness of fit. The number of sampling intervals during which abomasal emptying was fast, slow, or off was used to estimate total time spent in each abomasal emptying state during the 420-min time-course.

Statistical analysis of treatment effects on parameter values was performed in PROC MIXED of SAS (version 9.4, SAS Institute Inc., Cary, NC), with age as a repeated measure, where block, treatment, age, and a treatment $\times$ age interaction were considered fixed effects. Compound symmetry was assumed for the covariance structure and means were separated using the PDIFF option of SAS. Significance was declared at $P$ $\leq 0.05$, trends at $0.05<P \leq 0.1$.

The high treatment significantly decreased Ac clearance rate from plasma $\left(\mathrm{k}_{\mathrm{Ac}, \mathrm{UAc}}\right.$; Table 1$)$ whereas age tended to increase its clearance, an effect that has also been demonstrated in human infants (Anderson et al., 2000). The slow abomasal emptying rate tended to be slower on high, whereas the fast emptying rate was significantly slower on high. With slower abomasal emptying rates, the high treatment resulted in less time spent with abomasal outflow completely off and a tendency for more time where emptying occurred, either slow or fast. Therefore, the high treatment resulted in longer bouts of slower abomasal emptying. This effect of meal size on gastric emptying has been reported in several species (Delgado-Aros et al., 2004; Jackson et al., 2004; Métayer et al., 2004) and is attributed to intestinal 
Table 1. Least squares means of model parameter values for calves fed low $(4 \mathrm{~L} / \mathrm{d})$ or high $(8 \mathrm{~L} / \mathrm{d})$ volumes of milk replacer assessed from postprandial glucose, insulin, and acetaminophen time course data after a meal of 2 (low) or $4 \mathrm{~L}$ (high) at 4 and 7 wk of age

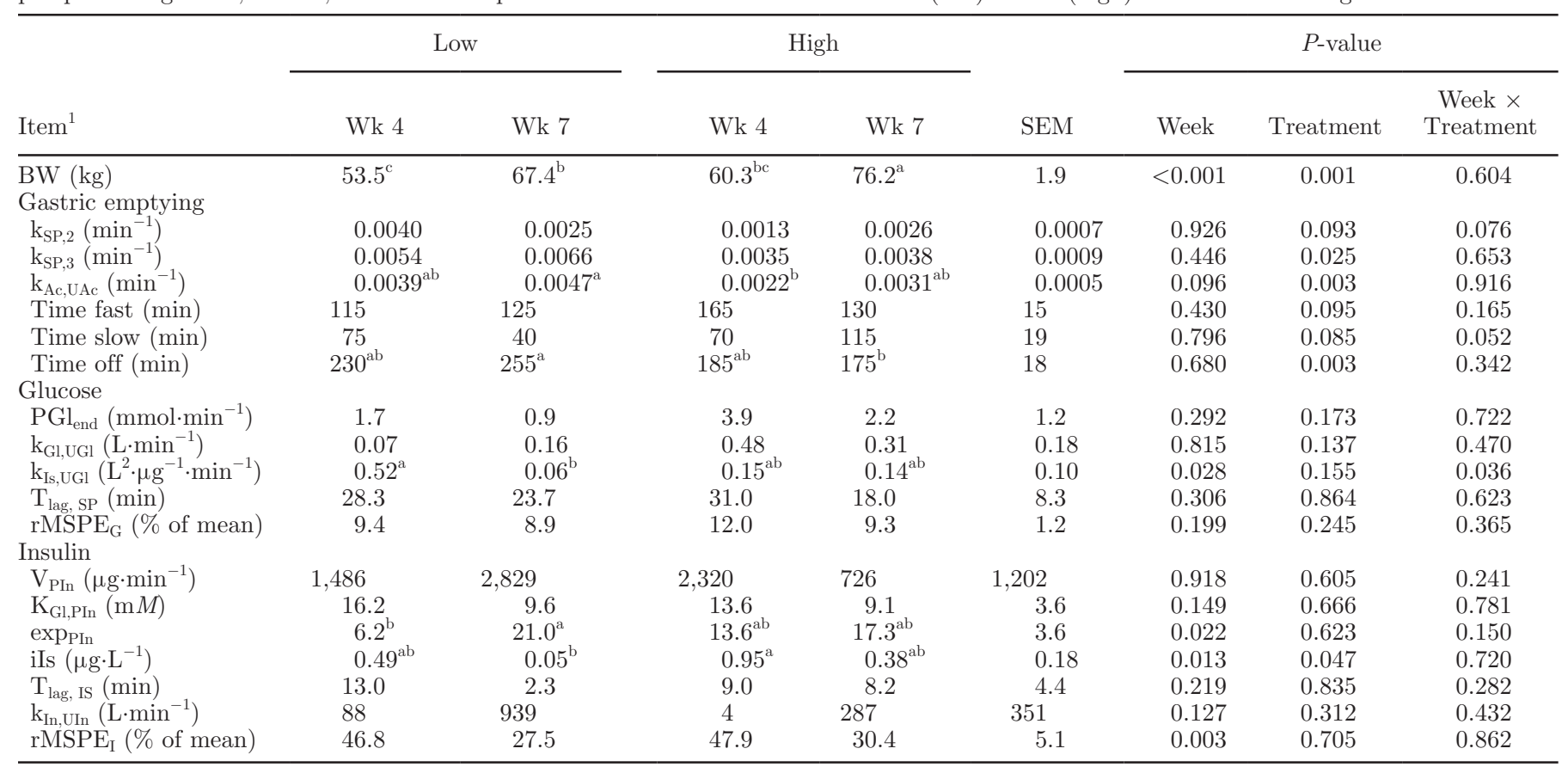

${ }^{\mathrm{a}-\mathrm{c}}$ Means with different superscripts are significantly different $(P \leq 0.05)$.

${ }^{1} \mathrm{k}_{\mathrm{SP}, 2}=$ first-order, slow abomasal emptying rate constant; $\mathrm{k}_{\mathrm{SP}, 3}=$ first-order, fast abomasal emptying rate constant; $\mathrm{k}_{\mathrm{Ac}, \mathrm{UAc}}=$ first-order acetaminophen $(\mathrm{Ac})$ utilization rate constant; $\mathrm{PGl}_{\text {end }}=$ rate of endogenous glucose production; $\mathrm{k}_{\mathrm{Gl} \text {.UGl }}=$ first-order glucose-dependent glucose utilization rate constant; $\mathrm{k}_{\mathrm{IS}, \mathrm{UGl}}=$ first-order insulin-dependent glucose utilization rate constant; $\mathrm{T}_{\text {lag.SP }}=$ absorption lag from stomach to plasma; $\mathrm{rMSPE}_{\mathrm{G}}=$ root mean square prediction error for plasma glucose; $\mathrm{V}_{\mathrm{PIn}}=$ maximal rate of insulin secretion; $\mathrm{k}_{\mathrm{Gl} \text {,PIn }}=$ glucose-dependent insulin secretion Michaelis constant; $\exp _{\text {PIn }}=$ Hill coefficient for glucose-dependent insulin secretion; iIs $=$ basal insulin signal mass prior to meal; $\mathrm{T}_{\text {lag.IS }}$

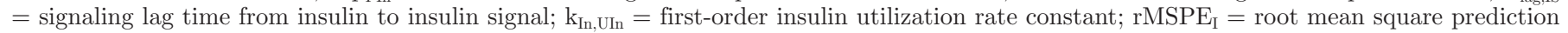
error for plasma insulin.

release of glucagon-like peptide-1 (GLP-1) in response to nutrients detected in the ileum and large intestine (Umapathysivam et al., 2014). In preweaned calves, GLP-1 secretion is stimulated by lactose to a greater extent than by casein (Sugino et al., 2014). We hypothesized that glucose-insulin dynamics could be different between postprandial and fasting states because of the involvement of gut hormones. We can infer from the abomasal emptying response to high versus low MR allowances that gut peptide release was perturbed.

Plasma glucose dynamics are a consequence of endogenous glucose production, exogenous glucose entry, and clearance. Basal endogenous glucose production $\left(\mathrm{PGl}_{\text {end }}\right)$ was not affected by treatment or age (Table 1 ). The exogenous glucose supply is influenced by the gastric emptying rate, which supplies carbohydrate to the intestine, and a time lag for digestion and absorption. Although abomasal emptying was slower on high compared with low MR intake, the time lag, $\mathrm{T}_{\text {lag.SP, was }}$ unaffected by treatment or age (Table 1).

Previous glucose tolerance tests in fasted calves have revealed that efficiency of clearance of an i.v. glucose dose typically declines between 1 and 8 wk of age (Col- vin et al., 1967; Webb et al., 1969; Depew et al., 1998), although not in all cases (Colvin et al., 1967; Benschop and Cant, 2009). In our experiment, glucose clearance following $2 \mathrm{~L}$ of MR intake decreased from 3.2 to $1.7 \%$ / min between wk 4 and 7 (MacPherson et al., 2016); however, we found no effect of age at high MR intake. Clearance at any point in time is dependent on the circulating concentrations of glucose, according to the so-called glucose effectiveness, and insulin, according to the insulin sensitivity. In turn, insulin concentration is dependent on the circulating concentration of glucose via a pancreatic responsiveness. All 3 of these parameters contribute to glucose clearance, and any one or combination thereof may be responsible for changes in glucose clearance as the calf ages or is exposed to different environments.

Whole-body glucose-dependent, insulin-independent glucose utilization, called glucose effectiveness, is described by the term $\mathrm{k}_{\mathrm{Gl} \text {.UGl }}$ and was not affected by treatment or age (Table 1). However, insulin-dependent glucose disposal $\left(\mathrm{k}_{\mathrm{Is}, \mathrm{UGl}}\right)$, which indicates insulin sensitivity, decreased between 4 and 7 wk of age on the low treatment. This effect of age on insulin sensitivity has 
been observed previously in veal calves (Hugi et al., 1998; Pantophlet et al., 2016) and contributes to the reduction in glucose clearance.

Intake of MR did not affect postprandial insulin sensitivity, which lies in contrast to previous studies that showed decreased preprandial insulin sensitivity in calves on higher MR allowances (Hugi et al., 1998; Bach et al., 2013; Yunta et al., 2015). Differences in postprandial gut peptide release between high and low treatments that were apparent from effects on abomasal emptying may have eliminated insulin sensitivity differences in our experiment. For example, GLP-1 appears to improve insulin sensitivity in the liver and periphery across numerous species (Ionut et al., 2008; Duez et al., 2009; Parlevliet et al., 2010).

Treatment had no effect on the $\exp _{\text {PIn }}$ parameter representing pancreatic responsiveness, but $\exp _{\text {PIn }}$ increased with age (Table 1). To our knowledge, effects of age on pancreatic responsiveness of calves have not been reported previously, although increases in plasma insulin AUC during i.v. glucose tolerance tests have been observed (Bach et al., 2013; Yunta et al., 2015; Pantophlet et al., 2016). Similarly, glucose-stimulated insulin secretion of pancreatic islets increased in suckling rat pups as they grew from 2 to $14 \mathrm{~d}$ of age (Foot et al., 2010). The elevated pancreatic responsiveness may be required to maintain glucose homeostasis in animals that are becoming progressively less insulin-sensitive.

Analysis of postprandial plasma glucose and insulin profiles after a MR meal revealed that higher volumes of MR intake increased maximal plasma glucose and insulin concentrations as well as postprandial insulin AUC (MacPherson et al., 2016). Fitting a mechanistic model of abomasal emptying and glucose-insulin dynamics to the postprandial curves showed no significant effects of MR intake on parameters associated with pancreatic responsiveness, insulin sensitivity, or glucose effectiveness. Thus, effects of high intake were primarily due to a shift in the abomasal emptying pattern toward longer bouts at a slower rate, the consequence of which was a spread in glucose absorption over a longer period so that postprandial glucose AUC was not different between high and low MR intakes. Model fits also showed that high MR intake increased the initial insulin signal (Table 1), which represents a downstream mediator of insulin effects, suggesting that prolonged nutrient delivery to the gut potentiated insulin action. This finding is similar to the observation in rats that simultaneous consumption of glucose and AA potentiates insulin action via hepatic parasympathetic activation, without altering insulin secretion (Afonso et al., 2016).

Between 4 and 7 wk of age, glucose clearance from plasma following a 2-L MR meal decreased (MacPherson et al., 2016). Mechanistic model fits revealed that this change was a result of lower whole-body insulin sensitivity, despite increased pancreatic responsiveness. Neither of these effects were apparent from i.v. glucose tolerance tests (MacPherson et al., 2016) and may have been related to postprandial gut hormone release. Effects of age on parameters of glucose-insulin dynamics were larger than effects of MR intake. Conversely, effects of MR intake on abomasal emptying were larger than effects of age. Alterations in abomasal emptying and glucose-insulin dynamics in the preweaning period could affect growth and postweaning performance. In this analysis, increased MR intake prolonged abomasal emptying and did not affect insulin sensitivity, whereas age decreased insulin sensitivity and enhanced pancreatic responsiveness.

\section{ACKNOWLEDGMENTS}

The authors acknowledge Bill Szkotnicki (University of Guelph) for his IT expertise. P. Stahel received scholarships from the Canadian Dairy Commission and the Ontario Ministry of Agriculture, Food and Rural Affairs.

\section{REFERENCES}

Afonso, R. A., J. M. Gaspar, I. Lamarao, W. W. Lautt, and M. P. Macedo. 2016. Postprandial insulin action relies on meal composition and hepatic parasympathetics: dependency on glucose and amino acids. J. Nutr. Biochem. 27:70-78.

Anderson, B. J., G. A. Woollard, and N. H. G. Holford. 2000. A model for size and age changes in the pharmacokinetics of paracetamol in neonates, infants and children. Br. J. Clin. Pharmacol. 50:125-134.

Bach, A., L. Domingo, C. Montoro, and M. Terré. 2013. Short communication: Insulin responsiveness is affected by the level of milk replacer offered to young calves. J. Dairy Sci. 96:4634-4637.

Benschop, D. L., and J. P. Cant. 2009. Developmental changes in clearance of intravenous doses of glucose, acetate and $\beta$-hydroxybutyrate from plasma of calves. Livest. Sci. 122:177-185.

Cant, J. P., V. N. Walsh, and R. J. Geor. 2005. Obtaining information on gastric emptying patterns in horses from appearance of an oral acetaminophen dose in blood plasma. Pages 69-83 in Nutrient Digestion and Utilization in Farm Animals: Modelling Approaches. E. Kebreab, J. Dijkstra, A. Bannink, W. J. J. Gerrits, and J. France, ed. CABI Publishing, Wallingford, UK.

Colvin, H. W., Jr., J. T. Attebery, and L. B. Daniels. 1967. Effect of diet on glucose tolerance of dairy calves one to thirteen weeks old J. Dairy Sci. 50:362-370.

Council of Europe. 1986. European Convention for the Protection of Vertebrate Animals used for Experimental and Other Scientific Purposes, European Treaty Series [1986, no 123] Strasbourg, France.

D'Alessio, D., W. Lu, W. Sun, S. Zheng, Q. Yang, R. Seeley, S. C. Woods, and P. Tso. 2007. Fasting and postprandial concentrations of GLP-1 in intestinal lymph and portal plasma: evidence of selective release of GLP-1 in the lymph system. Am. J. Physiol. Regul. Integr. Comp. Physiol. 293:R2163-R2169.

Delgado-Aros, S., M. Camilleri, F. Cremonini, I. Ferber, D. Stephens, and D. D. Burton. 2004. Contributions of gastric volumes and gastric emptying to meal size and postmeal symptoms of functional dyspepsia. Gastroenterology 127:1685-1694

Depew, C. L., L. D. Bunting, J. M. Fernandez, D. L. Thompson Jr., and R. W. Adkinson. 1998. Performance and metabolic responses 
of young dairy calves fed diets supplemented with chromium tripicolinate. J. Dairy Sci. 81:2916-2923.

Duez, H., A. C. Smith, C. Xiao, A. Giacca, L. Szeto, D. J. Drucker, and G. F. Lewis. 2009. Acute dipeptidyl peptidase-4 inhibition rapidly enhances insulin-mediated suppression of endogenous glucose production in mice. Endocrinology 150:56-62.

Foot, V. L., C. C. Richardson, W. Jefferson, P. D. Taylor, and M. R. Christie. 2010. Islets in early life are resistant to detrimental effects of a high-fat maternal diet: a study in rats. Horm. Metab. Res. 42:923-929.

Hugi, D., L. Tappy, R. Sauerwein, R. M. Bruckmaier, and J. W. Blum. 1998. Insulin-dependent glucose utilization in intensively milk-fed veal calves is modulated by supplemental lactose in an age-dependent manner. J. Nutr. 128:1023-1030.

Ionut, V., D. Zheng, D. Stefanovski, and R. N. Bergman. 2008. Exenatide can reduce glucose independent of islet hormones or gastric emptying. Am. J. Physiol. Endocrinol. Metab. 295:E269-E277.

Jackson, S. J., L. J. Bluck, and W. A. Coward. 2004. Use of isotopically labelled octanoic acid to assess the effect of meal size on gastric emptying. Rapid Commun. Mass Spectrom. 18:1003-1007.

Janus, K., B. Grochowina, J. Antoszek, S. Suszycki, and Z. Muszczynski. 2003. The effect of food or water deprivation on paracetamol pharmacokinetics in calves. J. Vet. Pharmacol. Ther. 26:291-296.

MacPherson, J. A. R., H. Berends, L. N. Leal, J. P. Cant, J. MartinTereso, and M. A. Steele. 2016. Effect of plane of milk replacer intake and age on glucose and insulin kinetics and abomasal emptying in female Holstein Friesian dairy calves fed twice daily. J. Dairy Sci. 99:8007-8017.

Marshall, T. S., P. D. Constable, S. S. Crochik, and T. Wittek. 2005. Determination of abomasal emptying rate in suckling calves by use of nuclear scintigraphy and acetaminophen absorption. Am. J. Vet. Res. 66:364-374.

Métayer, N., M. Lhôte, A. Bahr, N. D. Cohen, I. Kim, A. J. Roussel, and V. Julliand. 2004. Meal size and starch content affect gastric emptying in horses. Equine Vet. J. 36:436-440.

Pacini, G., and R. N. Bergman. 1986. MINMOD: a computer program to calculate insulin sensitivity and pancreatic responsivity from the frequently sampled intravenous glucose tolerance test. Comput. Methods Programs Biomed. 23:113-122.

Pantophlet, A. J., M. S. Gilbert, J. J. G. C. van den Borne, W. J. J. Gerrits, M. G. Priebe, and R. J. Vonk. 2016. Insulin sensitivity in calves decreases substantially during the first 3 months of life and is unaffected by weaning or fructo-oligosaccharide supplementation. J. Dairy Sci. 99:7602-7611.

Parlevliet, E. T., J. E. de Leeuw van Weenen, J. A. Romijn, and H. Pijl. 2010. GLP-1 treatment reduces endogenous insulin resistance via activation of central GLP-1 receptors in mice fed a high-fat diet. Am. J. Physiol. Endocrinol. Metab. 299:E318-E324.

Short, K. R., J. L. Vittone, M. L. Bigelow, D. N. Proctor, R. A. Rizza, J. M. Coenen-Schimke, and K. S. Nair. 2003. Impact of aerobic exercise training on age-related changes in insulin sensitivity and muscle oxidative capacity. Diabetes 52:1888-1896.

Stahel, P., J. P. Cant, J. A. R. MacPherson, H. Berends, and M. A. Steele. 2016. A mechanistic model of intermittent gastric emptying and glucose-insulin dynamics following a meal containing milk components. PLoS One 11:e0156443.

Sugino, T., M. Satoh, R. Fukumori, M. El-Sabagh, T. Obitsu, and K. Taniguchi. 2014. Effects of lactose and casein on plasma glucagonlike peptide-1 (7-36) amide concentrations in calves before weaning. Proc. 16th AAAP Anim. Sci. Congr. 2:1785-1788.

Umapathysivam, M. M. M. Y. Lee, K. L. Jones, C. E. Annink, C. E. Cousins, L. G. Trahair, C. K. Rayner, M. J. Chapman, M. A. Nauck, M. Horowitz, and A. M. Deane. 2014. Comparative effects of prolonged and intermittent stimulation of the glucagonlike peptide 1 receptor on gastric emptying and glycemia. Diabetes 63:785-790.

Webb, D. W., H. H. Head, and C. J. Wilcox. 1969. Effect of age and diet on fasting blood and plasma glucose levels, plasma nonesterified fatty acid levels, and glucose tolerance in dairy calves. J. Dairy Sci. 52:2007-2013.

Woerle, H. J., L. Carniero, A. Derani, B. Goeke, and J. Schirra. 2012. The role of endogenous incretin secretion as amplifier of glucosestimulated insulin secretion in healthy subjects and patients with type 2 diabetes. Diabetes 61:2349-2358.

Wolever, T. M. S., and C. Mehling. 2002. High-carbohydrate-low glycaemic index dietary advice improves glucose disposition in subjects with impaired glucose tolerance. Br. J. Nutr. 87:477-487.

Yunta, C., M. Terré, and A. Bach. 2015. Short- and medium-term changes in performance and metabolism of dairy calves offered different amount of milk replacers. J. Livest. Sci. 181:249-255. 